\title{
Chronic Neck Pain and Its Relationship with Mental Stress: Is Regular Physical Exercise a Protective Factor?
}

\author{
Galo Camacho and Tomas Nakazato
}

CEDOMUH, Lima, Peru

\begin{abstract}
Introduction: Chronic neck pain (CNP) is a common complaint and a main cause of disability, being known its relationship with mental stress (ME). We aimed to know the prevalence of CNP in the Peruvian adult population, its relationship with stress, and to observe if regular physical exercise (PE) could be a protective factor. Methods: A nationwide survey was conducted. CNP was considered for those who answered having it at least once a week for the last six months, ME for those having at least five out of eight common symptoms, and the lack of regular PE for those having made physical exercise once a week or less. Results: A total of 1,244 adults responded. Prevalence of CNP was 20.9\%. We found an odds ratio (OR) of 7.773 (95\%CI, 4.656-12.980) between CNP and ME, and an OR of $1.152(95 \% \mathrm{CI}, 0.842-1.578)$ for the lack of regular PE. Values maintained after adjusting for covariates (age $\geq 25$ years-old, female sex and socioeconomical level C/D/E). Conclusions: A fifth of the adult Peruvian population refer CNP, constituting a major health problem in this country. We found a strong association in people with ME, but regular PE is not associated as a protective factor.
\end{abstract}

Key words: Neck pain, cervicalgia, mental stress, physical exercise.

\section{Introduction}

Neck pain (NP) or cervicalgia is a very common complaint. It is only surpassed by low back pain as the most frequent cause of musculoskeletal pathology in population surveys and in the primary health care systems, and just like this one, it can give rise to many disabilities and absenteeism [1]. Although it is true that the majority of cases are benign, epidemiological studies indicate that pain in the cervical region is becoming increasingly prevalent throughout the world and, therefore, should be considered a public health problem [2, 3]. In the United States of NA, it is currently the sixth cause of years lost for disability [4]. Most individuals with NP do not usually seek medical attention. However, those who do (due to the severity or persistence of symptoms) lead to a disproportionate

Corresponding author: Galo Camacho, MD, Dr., assistant physician, research fields: clinic specialized in muscle and bone pain, medical surgeon specialized in physical medicine and rehabilitation. amount of health system expenditures [5-7]. Chronic pain of the cervical spine is related to a significant economic and social impact that is increasing over the years. For this reason, studies should focus on chronic neck pain (CNP), as this condition can seriously affect the quality of life of patients (who usually receive inadequate medical care) $[8,9]$. We did not find in the literature an updated report about the prevalence of CNP in Peru.

Mental stress (MS) is defined as an unpleasant emotional experience, accompanied by predictable biochemical, physiological and behavioral changes, described as the feeling of being overwhelmed, anguished and exhausted [10,11]. It can affect people of all ages, genders and strata, and can lead to psychological and physical disorders. This state of mind can be beneficial in some circumstances, promoting the impulse and energy necessary for people to face situations such as a test in a study center or to meet deadlines for an entrusted task in a job. However, 
an excessive amount of MS can result in alterations to our health, affecting the immune, cardiovascular, neuroendocrine and central nervous systems [12].

MS also produces muscle tension, and it seems to be a very important factor in cervical disorders [13]. It has been possible to establish the existence of motor activity by inducing MS. The trapezius muscle (the largest in the neck) shows a clear contraction response when triggering a cognitive stress, being this response dose-dependent [14]. The brain limbic component, which controls the autonomic nervous system, also has a great influence on the medullary motor system (including segmental and proprioceptive interneurons), triggering mechanisms for rhythmic activities (for example, breathing, chills and cardiovascular regulation). In striated muscles, the influence of the limbic system varies from strong control over respiratory muscles such as the diaphragm to relatively minor influences on the peripheral flexor muscles. The trapezius seems to also receive a great influence from the limbic components [15].

The association between MS and NP is well known $[16,17]$ and the first one is an independent and much more important factor than other work variables, such as hours worked in front of a computer, weight lifting or using tools that vibrate or driving vehicles, to induce the latter $[18,19]$. CNP pain is related to a significant economic and social impact that is increasing [20] and although it is true that a large number of cases resolve spontaneously or with treatment, about 50\% will experience frequent relapses or persistent pain [5].

Physical exercise (PE) is often recommended as a way to combat MS, and some studies suggest that regular physical activity has a protective effect against its detrimental effects [21, 22]. It could be assumed that, since there is an association between MS and NP, regular PE could also decrease the prevalence of NP. However, systematic reviews have not supported this assumption [23, 24].

The present study aimed to know the prevalence of CNP in the Peruvian adult population, what was the magnitude of MS symptoms as a factor associated with this entity, and to observe whether regular PE could be a factor of protection against it.

\section{Methods}

A nationwide survey was conducted during the fourth week of November 2016 through the market research company GfK Peru. The investigation was carried out with a structured questionnaire and closed questions. The type of sampling was probabilistic and stratified by regions at a national level (Lima — Capital of the country, North, Center, South and East regions), multi-stage with random start and systematic selection of housing (the amount and characteristics of the samples were described in the results section-Table 1). Age, sex and socioeconomic status were recorded as covariates.

The dependent variable was CNP. NP is felt by the patients at the neck region, in the area between the head and cervical spine (known as the nape) and/or in the upper part of the shoulders where the upper trapezius muscle is located (the largest in the region). Chronic musculoskeletal pain is the one that persists beyond the normal healing time, which is usually 3 months, but for research purposes it is preferred to take 6 months as illness time [25], and that was why we chose the latter for our definition of CNP. To identify the cases, the interviewees were asked the following question: "Thinking in the last six months, have you had pain in the neck, the nape and/or in the upper part of the shoulder?". In response, the participants were given four alternatives: (1) I have never had neck pain, or I have had it very rarely; (2) I have had pain once a month on average; (3) I have had pain once a week on average; (4) I have pain daily or almost daily. The person was considered to have CNP, when answering affirmatively to option 3 or 4 .

The independent variable was MS. An index of eight typical stress symptoms extracted from a study published by the Department of Physical Medicine and Rehabilitation of the University Hospital of Turku in 
Finland [26] was used (data from the adolescent health and lifestyle survey 2003, a nation-wide monitoring system of Finnish adolescents, and used these stress index to control this important confounding factor). In our case, the participants were told: "I am going to read some discomforts that may occur in people. I would like you to tell me if you have any of these problems at least once a week in the last six months": (1) Headache or migraines; (2) Stomach pain or heartburn; (3) Feeling of being tired or apathetic without apparent reason; (4) Difficulty to sleep or wake up at dawn for no apparent reason; (5) Irritability or feeling of being upset for no apparent reason; (6) Nervousness or anxiety; (7) Dizziness or nausea for no apparent reason; (8) Tremor in hands. It was considered that the person had MS if he/she answered affirmatively to 5 or more of the mentioned symptoms.

The second independent variable was regular PE. The participants were asked: "Tell me, how often do you exercise or do any physical activity?". In response, the participants were given four alternatives: (1) Less than once a week; (2) Once a week; (3) From two to three times a week; (4) Every day. It was considered that the person did not regularly perform PE when answering affirmatively to option 1 or 2 .

Simple and multivariate logistic regression was used to calculate Odds Ratio (OR) using the IBM SPSS 20 statistical package.

\section{Results}

A total of 1244 adults responded to the survey, which is a representative sample of the Peruvian population. The characteristics can be seen in Table 1 .

The prevalence of CNP was $20.9 \%$ (252 cases). The prevalence in women was higher than in men $(23.8 \%$ versus $18.9 \%, p<0.05)$. The prevalence in young people between 18 and 24 years was $15.0 \%$, in adults between 25 to 39 years was $20.7 \%$ and in those over 40 years was $23.8 \%$ (these differences were significant, $p$ $<0.05)$.

We found 47 cases of people who presented 5 or more symptoms of MS associated with CNP (4.10\%). The OR found was 7.773 (95\% CI from 4.654 to 12.980). There were also 154 cases of people with a lack of regular PE who presented CNP (15\%). The OR found was 1.152 (95\% CI from 0.842 to 1.578 ), see Table 2.

When performing the adjustment with covariates

Table 1 Characteristics of the sample studied. National survey. Peru, November 2016.

\begin{tabular}{lll}
\hline Total: 1,244 adults & No. & $\%$ \\
\hline Region & & \\
\hline Lima & 431 & 34.65 \\
North & 298 & 23.95 \\
Center & 122 & 9.81 \\
South & 246 & 19.77 \\
East & 147 & 11.82 \\
\hline Zone & & \\
\hline Urban & 979 & 78.70 \\
Rural & 265 & 21.30 \\
\hline Age group (years) & & \\
\hline 18-24 & 250 & 20.10 \\
25-39 & 464 & 37.30 \\
40 to more & 530 & 42.60 \\
\hline Sex & & 49.76 \\
\hline Men & 619 & 50.24 \\
Women & 625 & 13.50 \\
\hline Socioeconomic level & & 26.53 \\
\hline A/B & 168 & 59.97 \\
C & 330 & \\
D/E & 746 & \\
\hline
\end{tabular}


Table 2 Risk of CNP due to MS and lack of regular PE.

\begin{tabular}{lllllll}
\hline & \multicolumn{3}{c}{ With CNP } & & \multicolumn{2}{c}{$95 \%$ confidence interval } \\
\cline { 2 - 6 } & No. & $\%$ & $p$ & OR & Low. Lim. & $\begin{array}{c}\text { Upp. } \\
\text { Lim. }\end{array}$ \\
\hline With $\geq 5$ symptoms of ME & 47 & 4.10 & 0.000 & 7.773 & 4.654 & 12.980 \\
With lack of regular PE & 154 & 15.05 & 0.377 & 1.152 & 0.842 & 1.578 \\
\hline
\end{tabular}

Table 3 Risk of CNP due to MS and lack of regular PE, adjusted to age, sex and SE level.

\begin{tabular}{lllll}
\hline & $p$ & OR & \multicolumn{2}{c}{ 95\% CI } \\
\cline { 4 - 5 } & & & Low. Lim. & Upp. \\
Lim.
\end{tabular}

that are associated with an increased risk of cervical pain, such as age over 25 years, female sex and socioeconomic level $\mathrm{C}$ and $\mathrm{D} / \mathrm{E}$, the values found were maintained, see Table 3.

\section{Discussion}

About a fifth of the total population studied reported having had CNP. Although cervicalgia is very common, a plausible medical cause has not yet been determined, especially when it becomes a chronic problem. The only thing that is clear is that musculoskeletal pain has many sides and, therefore, it cannot be easily explained using simplified models. It must be viewed in a multidimensional manner, covering biological, psychological and social aspects [17]. MS is one of the most common psychological factors associated with pain.

This is the first national study in Peru on the association between CNP and ME and, as expected, a strong association was found in the adult population. People with 5 or more MS symptoms had an odds 7 times higher compared to the group that had less than 5 symptoms, which was maintained by adjusting the results with age, sex and socioeconomic status.

As mentioned earlier, regular PE has a protective factor against ME, and one may think that, given the association between the latter with CNP, we should recommend patients to perform $\mathrm{PE}$ to alleviate CNP.
But, in our study, no significant association was found between CNP and the lack of regular PE. It leads to think that physical activity would not be a protective factor. This agrees with some studies that have observed that PE does not diminish the pain of neck and may even exacerbate it $[23,24,27]$. It may be due to the fact that vigorous exercises and contact sports could produce more musculoskeletal injuries and, therefore, worsen the symptoms. Maybe selected exercises could help, since a randomized study found that doing specific exercises to strengthen the neck muscles and aerobic exercise on a stationary bicycle alleviate NP [28]. For this reason, it can be considered some rehabilitation exercises for the neck associated with low impact aerobics as a treatment for CNP, but we cannot be recommended to do any type of PE in an attempt to relieve it.

Our study has some limitations. The diagnosis of CNP and MS were based on the subjective responses of the participants and on a series of related symptoms that the participant communicated to the interviewer. The work carried out has found a strong association, but it did not allow us to establish whether MS was the cause or the consequence of having chronic CNP. As the cases found have not been very frequent, we have interpreted the OR in a similar way to the relative risk, being aware of the difference between both measures of association. 


\section{Conclusions}

CNP is a common complaint in the adult Peruvian population and it deserves a great attention from our national health care system. Based on our findings, there is a strong association with MS and its management of should be considered as a key component for the treatment of CNP. Our results do not support the recommendation of regular PE to relieve it. Future studies are needed to confirm these recommendations.

\section{Acknowledgements}

We thank the Market Research Company GfK Peru for carrying out the survey and the statistical analysis, especially Hernán Chaparro (Director) and Antonio Ruiz (Statistician).

\section{Conflicts of Interest}

The material contained in this manuscript has not been previously published or submitted to another biomedical journal. Funding was obtained through own resources. We declare no conflicts of interest in this study.

\section{References}

[1] Mäkela, M., Heliövaara, M., Sievers, K., Impivaara, O., Knekt, P., and Aromaa, A. 1991. "Prevalence, Determinants, and Consecuences of Chronic Neck Pain in Finland." Am J Epidemiol 134 (11): 1356-67.

[2] Protani, M., Hoy, D., and Buchbinder, R. 2010. "The Epindemiology of Neck Pain." Clin Rheumatol 24 (6): 783-92.

[3] Fejer, R., KyviK, K., and Hartvigsen, J. 2006. "The Prevalence of Neck Pain in the World Population: A Sistematic Critical Review of the Literature." Eur Spine $J$ 15: 834-48.

[4] The US Burden of Disease Collaborators. 2018. "The State of US Health, 1990-2016. Burden of Diesases, Injuries, and Risk Factors among US States.” JAMA 319 (14): 1444-72.

[5] Cohen, S. 2015. "Epidemiology, Diagnosis, and Treatment of Neck Pain." Mayo Clin Proc 90 (2): 284-99.

[6] Singh, V., Manchikanti, L., Datta, S., Cohen, S., and Hirsch, J. 2009. "Comprehensive Review of Epidemiologý, Scope and Impact of Spinal Pain.” Pain
Physician 12: E35-E70.

[7] Ferrari, R., and Russell, A. 2003. "Neck Pain." Best Pract Res Clin Rheumatol 17 (1): 57-70.

[8] Loeser, J., and Melzack, R. 1999. "Pain: An Overview." The Lancet 353 (9164): 1607-9.

[9] Breivik, H., Collet, B., Ventafridda, V., Cohen, R., and Gallacher, D. 2006. "Survey of Chronico Pain in Europe: Prevalence, Impact on Daily Life, and Treatment." Eur $J$ Pain 10: 287-333.

[10] Baum, A. 1990. "Stress, Intrusive Imagery, and Chronic Distress." Health Psychology 6: 653-75.

[11] American Psychological Association (APA). 2017. [Online]. Available: http://www.apa.org/helpcenter/understanding-chronic-str ess.aspx.

[12] Anderson, N. "Levels of Analysis in Health Science: A Framework for Integrating Sociobehavioral and Biomedical Research." Annals of the New York Academy of Sciences 840: 563-76.

[13] Melin, B., and Lundberg, U. 1997. "A Biopsychosocial Approach to Work-Stress and Musculoskeletal Disorders.' Journal of Psychophysiology 11 (3): 238-47.

[14] Waersted, M., and Westgaard, R. H. 1996. "Attention-related Muscle Activity in Different Body Regions during VDU Work with Minimal Physical Activity." Ergonomics 36: 661-76.

[15] Westgaard, R. 1999. "Effects of Physical and Mental Stressors on Muscle Pain." Scand J Work Environ Health 25 (4): 19-24.

[16] Demyttenaere, K., Bruffaerts, R., Lee, S., Posada-Villa, J., Kovess, V., Angermeyer, M. C., Levinson, D., de Girolamo, G., Nakane, H., Mneimneh, Z., Lara, C., de Graaf, R., Scott, K. M., Gureje, O., Stein, D. J., Haro, J. M., Bromet, E. J., Kessler, R. C., Alonso, J., and Von Korff, M. 2007. "Mental Disorders among Persons with Chronic Back or Neck Pain: Results from the World Mental Health Surveys." Pain 129 (3): 332-42.

[17] Linton, S. J. 2000. “A Review of Psychological Risk Factors in Back and Neck Pain.” Spine 25 (9): 1148-56.

[18] Evans, O., and Patterson, K. 2000. "Predictors of Neck and Shoulder Pain in Non-secretarial Computer Users." International Journal of Industrial Ergonomics 26 (3): 357-65.

[19] Palmer, K., Walker-Bone, K., Griffin, M., Syddall, H., Pannett, B., Coggon, D., and Cooper, C. 2001. "Prevalence and Occupational Associations of Neck Pain in the British Population." Scandinavian Journal of Work Environment 27 (1): 49-56.

[20] Sing, V., Manchikanti, L., Datta, S., Cohen, S., and Hirsch, J. 2009. "Comprehensive Reviewe of Epidemiology, Scope and Impact of Spinal Pain." Pain Physician 12: E35-E70. 


\section{Is Regular Physical Exercise a Protective Factor?}

[21] Salmon, P. 2001. "Effects of Physical Exercise on Anxiety, Depression, and Sensitivity to Stress: A Unifying Theory." Clinical Psychology Review 21 (1): 33-61.

[22] Scully, D., Kremer, J., Meade, M. M., Graham, R., and Dudgeon, K. 1998. "Physical Exercise and Phsychological Well Being: A Critical Review." Br J Sports Med 32: 111-20.

[23] Carroll, L. J. et al. 2009. "Course and Prognostic Factors for Neck Pain in the General Population: Results of the Bone and Joint Decade 2000-2010 Task Force on Neck Pain and Its Associated Disorders." Journal of Manipulative and Physiological Therapeutics 32 (2): S87-S96.

[24] Sitthipornvorakul, E., Janwantanakul, P., Purepong, N., Pensri, P., and van der Beek, A. J. 2011. "The Association between Physical Activity and Neck and Low Back Pain: A Sistematic Review.” Eur Spine J 20: 677-89.
[25] International Association for the Study of Pain (IASP). 2011. [Online]. Available: http://www.iasp-pain.org/PublicationsNews/Content.aspx ?ItemNumber $=1673 \&$ navItemNumber $=677$.

[26] Hakala, P. T., Rimpela, A. H., Sarrni, L. A., and Salminen, J. J. 2006. "Frequent Computer-related Activities Increase the Risk of Neck-Shoulder and Low Back Pain in Adolescents.” Eur J Public Health 16 (5): 536-41.

[27] Kujala, U. M., Taimela, S., and Viljanen, T. 1999. "Leisure Physical Activity and Various Pain Symptoms among Adolescents." Br J Sports Med 33: 325-8.

[28] Andersen, L. L., Kjaer, M., Sogaard, K., Hansen, L., Kryger, A. I., and Sjogaard, G. 2008. "Effect of Two Contrasting Types of Physical Exercise on Chronic Neck Muscle Pain." Arthrtis \& Rheumatism (Athritis Care \& Research) 59 (1): 84-91. 